\title{
Uptake of phenol from aqueous solution by burned water hyacinth
}

\author{
Mohammed Tamez Uddin, Mohammed Saiful Islam, Mohammed Akhtarul Islam, Mohammed \\ Zainal Abedin
}

Shahjalal University of Science \& Technology, Department of Chemical Engineering \& Polymer Science, Sylhet-3114, Bangladesh, e-mail: mtuddin_cep@yahoo.com

\begin{abstract}
The potential of burned water hyacinth (BWH) for phenol adsorption from aqueous solution was studied. Batch kinetic and isotherm studies were carried out under varying experimental conditions of contact time, phenol concentration, adsorbent dosage and $\mathrm{pH}$. The $\mathrm{pH}$ at the point of zero charge $\left(\mathrm{pH}_{\mathrm{pZC}}\right)$ of the adsorbent was determined by the titration method and the value of $8.8 \pm 0.2$ was obtained. The FTIR of the adsorbent was carried out in order to find the potential adsorption sites for the interaction with phenol molecules. The Freundlich and Langmuir adsorption models were used for the mathematical description of adsorption equilibrium and it was found that the experimental data fitted very well to the Langmuir model. Maximum adsorption capacity of the adsorbent was found to be $30.49 \mathrm{mg} / \mathrm{g}$. Batch adsorption models, based on the assumption of the pseudo-first-order and pseudo-second-order models, were applied to examine the kinetics of the adsorption. The results showed that kinetic data closely followed the pseudo-second-order model.
\end{abstract}

Keywords: Phenol, Adsorption, Burned water hyacinth, Equilibrium, Adsorption Kinetics.

\section{INTRODUCTION}

Phenols are common contaminants in wastewater generated from oil, gasoline, coal, paper, textile, petroleum, petrochemicals, pharmaceuticals, phenol producing industries and plants, which are processing phenols to plastics. They are considered to be one of the priority pollutants in wastewater, because they are harmful to organisms even at low concentrations. Many phenols have been classified as hazardous pollutants because of their potential toxicity to human health. Human consumption of phenol contaminant water can cause severe pain leading to the damage of the capiliaries, ultimately causing death. Its presence in water supplies is noticed as bad taste and odor ${ }^{1}$. In the presence of chlorine in drinking water, phenols form chlorophenol, which has a medicinal taste and which is quite pronounced and objectionable. Therefore, Environmental Protection Agency regulations call for lowering phenol content in wastewater to less than $1 \mathrm{mg} / \mathrm{L}^{2}$.

There are many methods, such as, adsorption, microbial degradation, chemical oxidation, precipitation, ion exchange and solvent extraction to remove phenols from the aqueous solution. Adsorption is an effective separation process for treating industrial and domestic effluents. Activated carbon is the most widely used adsorbent. It has the advantage of high adsorption capacity for organic compounds, but its use is usually limited due to its high $\operatorname{cost}^{3-5}$.

The adsorption characteristics of phenol on various adsorbents have previously been extensively investigated for many purposes of separation and purification. However, most of the work regarded the adsorption behavior of the activated carbon. The adsorption of phenol from the aqueous solution by using carbonized beet pulp was investigated ${ }^{6}$. The result indicated that the adsorption capacity of the adsorbent was considerably affected by the initial $\mathrm{pH}$, temperature and the initial phenol concentration. The equilibrium data were well described by the Freundlich model and the pseudo-second-order equation provided the better correlation for the adsorption data. In another experiment, it was reported that the adsorption of phenol onto chitin was endothermic and increased with temperature ${ }^{7}$. The increase in active bentonites mass or the initial $\mathrm{pH}$ of the solution also resulted in the more significant phenol removal from the solution ${ }^{8}$. It was also indicated that peat, fly ash and bentonite were found to adsorb $46.1 \%, 41.6 \%$ and $42.5 \%$ phenol, respectively, from the solution of the initial concentration of approximately $1 \mathrm{mg} / \mathrm{L}^{9}$. Other adsorbents used to remove phenol from the aqueous solution are bentonite ${ }^{10}$, silica gel, activated alumina and activated carbon ${ }^{11}$, titanium oxide $\left(\mathrm{TiO}_{2}\right)^{12}$, activated carbon derived from solid waste such as PET, waste tires, refused derived fuel and waste generated during lactic acid fermentation from garbage ${ }^{13}$, powdered and granular activated carbon prepared from Eucalyptus wood ${ }^{14}$, mesoporous activated carbon prepared from waste tires ${ }^{15}$, aspergillus niger biomass ${ }^{16}$, pumice ${ }^{17}$ and papermill sludge ${ }^{\mathbf{1 8}}$.

Water hyacinth $(\mathrm{WH})$ is available in the river and pond in Bangladesh. It grows and reproduces at a very high rate and is considered the worst aquatic plant ${ }^{19}$. The dense mats of WH float on the water surface, blocking navigation and interfere with irrigation, fishing, recreation, and power generation. These mats also prevent sunlight penetration and reduce the aeration of water, leading to oxygen deficiency, competitively exclude submerged plants, and reduce biological diversity. The control of WH invasion, mainly by mechanical collection and dumping is expensive and presents a solid waste problem to get rid of the WH dumps. Much research has been conducted in efforts to find application for the dumped WH. This includes the research on biogas generation ${ }^{20}$, fish feed ${ }^{19}$ and animal feed ${ }^{21}$.

In this study, burned water hyacinth (BWH) is used as an adsorbent to remove phenol from aqueous solution. The objective of this study was to produce burned water hyacinth as an adsorbent for the adsorption of phenol and to investigate the effects of initial phenol concentration, contact time, $\mathrm{pH}$ and adsorbent dosage on the adsorption of phenol on burned water hyacinth. The $\mathrm{pH}_{\mathrm{PZC}}$ of the adsorbent was determined by the titration method. The equilibrium isotherm data were fitted to Langmuir and 
Freundlich equations and constants of isotherm equations were determined. Adsorption kinetics of phenol onto burned water hyacinth was also analyzed by using the pseudo-first-order and pseudo-second-order models to the data.

\section{MATERIALS AND METHODS}

\section{Materials}

The water hyacinth was collected from the local ponds. The roots of the collected water hyacinth were separated and washed thoroughly with water for several times to remove the earthy matter and all the dirt particles. It was then dried in an oven at the temperature of $105^{\circ} \mathrm{C}$ for about 16 hours. The dried roots were then burned at $300^{\circ} \mathrm{C}$. The remaining was then ground and sieved to the particle size of $180-300 \mu \mathrm{m}$, and stored in a plastic bottle for use as the adsorbent.

\section{Chemicals}

A stock solution of $1000 \mathrm{mg} / \mathrm{L}$ phenol was prepared by dissolving $1.0 \mathrm{~g}$ of the analytical reagent grade phenol (Sigma Chemical Co., Germany) in $1 \mathrm{~L}$ distilled water. The test solution of desired concentration was then prepared by diluting the stock solution. The $\mathrm{pH}$ of the solution was adjusted to the required value ( $\mathrm{pH} 6 \pm 0.5$ ) with $0.1 \mathrm{~N} \mathrm{HCl}$ and $0.1 \mathrm{~N} \mathrm{NaOH}$ solutions before mixing with the adsorbent. While there was no significant change observed on $\mathrm{pH}$ in the equilibrium, the uptake $\mathrm{pH}$ was assumed constant during the experiments.

\section{Sorption experiments}

\section{Determination of $p H P Z C$ of the adsorbent}

The surface charge $(\mathrm{Q})$ and the $\mathrm{pH}_{\mathrm{PZC}}$ of the adsorbent in the aqueous phase were analyzed with different system $\mathrm{pH}$ values by using the titration method described elsewhere ${ }^{22} .0 .1 \mathrm{~g}$ adsorbent was taken in $50 \mathrm{ml} 0.1 \mathrm{M} \mathrm{KNO}_{3}$ solution and agitated with a magnetic stirrer. Then the $\mathrm{pH}$ of the solution was measured after the equilibrium time of 30 minute. The titration was carried out with $0.1 \mathrm{M}$ $\mathrm{NaOH}$ and $0.1 \mathrm{M} \mathrm{HCl}$, respectively.

Fourier transform infrared spectroscopy (FTIR) analysis Fourier transform infrared spectroscopy (FTIR) of the adsorbent was conducted by using the FTIR spectrophotometer (Model: FTIR 2000, Shimadzu, Kyoto, Japan). About $150 \mathrm{mg} \mathrm{KBr}$ disks containing approximately $2 \%$ of JLP samples was prepared shortly before recording the FTIR spectra in the range of $400-4000 \mathrm{~cm}^{-1}$ and with a resolution of $4 \mathrm{~cm}^{-1}$. The resulting spectra were the average of 30 scans.

\section{Effect of $p H$}

The effect of $\mathrm{pH}$ on the amount of phenol removal was analyzed over the $\mathrm{pH}$ range of $2.5-12$. In this study, 150 $\mathrm{ml}$ of phenol solution of $50 \mathrm{mg} / \mathrm{L}$ was taken in the stopper plastic conical flask and was agitated with $1.0 \mathrm{~g}$ of BWH using the flash shaker (Stuart Scientific Co. Ltd. Model $\mathrm{SF} 1, \mathrm{U} . \mathrm{K}$.) at room temperature $\left(27 \pm 2^{\circ} \mathrm{C}\right)$. Agitation was made for $5 \mathrm{~h}$ at constant oscillation of $500 \mathrm{osc} / \mathrm{min}$. The samples were then centrifuged, and the left out concentrations in the supernatant solutions were analyzed using the spectrophotometric method. Phenol at alkaline condition $(\mathrm{pH} 7.9 \pm 0.1)$ reacts with potassium ferricyanide and 4-aminophenazone to form a red colored complex. The absorbance of the complex at a maximum wavelength of $505 \mathrm{~nm}$ is a direct measurement of phenol concentration. The solution was made alkaline to develop color by the concentrated ammonia solution.

Each experiment was repeated three times and the average value of the measured phenol was plotted. The deviation of each measurement was less than $2 \%$ from the average value.

\section{Effect of adsorbent dosage}

The effect of BWH mass on the amount of removal of phenol solution was obtained by contacting $150 \mathrm{ml}$ of phenol solution of the initial concentration of $70 \mathrm{mg} / \mathrm{L}$ with different weighed amount $(0.2,0.4,0.6,0.8,1.0,1.2$, 1.4 , and $1.6 \mathrm{~g}$ ) of BWH in the stopper conical flask. Each sample was then agitated for $5 \mathrm{~h}$ at a constant oscillation of $500 \mathrm{osc} / \mathrm{min}$. The samples were then centrifuged and the concentrations in the supernatant phenol solutions were then analyzed as before.

\section{Adsorption equilibrium}

Equilibrium studies were carried out by contacting $0.75 \mathrm{~g}$ of BWH with $150 \mathrm{ml}$ of phenol solution of different initial concentrations $(40,50,60,70,80,90,100$ and 110 $\mathrm{mg} / \mathrm{L}$ ) in $250 \mathrm{ml}$ stopper conical flasks. The samples were then shaken at a constant oscillation of $500 \mathrm{osc} / \mathrm{min}$ for $5 \mathrm{~h}$ at $27 \pm 2^{\circ} \mathrm{C}$. After equilibrium the concentrations in the samples were analyzed as before.

\section{Adsorption kinetics}

Sorption kinetics experiments were carried out by contacting $200 \mathrm{ml}$ phenol solution of different initial concentrations ranging from 50 to $70 \mathrm{mg} / \mathrm{L}$ with $0.5 \mathrm{~g} \mathrm{BWH}$ in a $250 \mathrm{ml}$ stoppered conical flask. The samples were then shaken at a constant oscillation speed of $500 \mathrm{osc} / \mathrm{min}$ for $5 \mathrm{~h}$. Samples were then pipetted out at different time intervals. The collected samples were then centrifuged and the concentration in the supernatant solution was analyzed as before.

\section{RESULTS AND DISCUSSIONS}

\section{Determination of $\mathrm{pH}_{\mathrm{PzC}}$ of the adsorbent}

The surface charge $Q$ of the adsorbent was calculated from the experimental titration data according to the following equation ${ }^{22}$.

$Q=\frac{1}{w}\left(C_{A}-C_{B}-\left[H^{+}\right]-\left[O H^{-}\right]\right)$

where, $w$ - dry weight of adsorbent in aqueous system $\left(\mathrm{gL}^{-1}\right) ; C_{A}$ is the concentration of added acid in the aqueous system $(\mathrm{mol} / \mathrm{L}) ; C_{B}$ is the concentration of the added base in the aqueous system $(\mathrm{mol} / \mathrm{L}) ;\left[\mathrm{H}^{+}\right]$is the concentration of $\mathrm{H}^{+}(\mathrm{mol} / \mathrm{L}) ;\left[\mathrm{OH}^{-}\right]$is the concentration of $\mathrm{OH}^{-}$ $(\mathrm{mol} / \mathrm{L})$. Then the $\mathrm{pH}$ value at the point of zero charge was determined by plotting $Q$ versus $\mathrm{pH}$. Fig.1 shows the surface charge of the adsorbent as a function of $\mathrm{pH}$. From Fig. 1 it is obvious that the surface charge of the adsorbent at $\mathrm{pH} 8.8 \pm 0.2$ is zero. Hence the $\mathrm{pH}_{\mathrm{PZC}}$ of the $\mathrm{BWH}$ is $8.8 \pm 0.2$. 


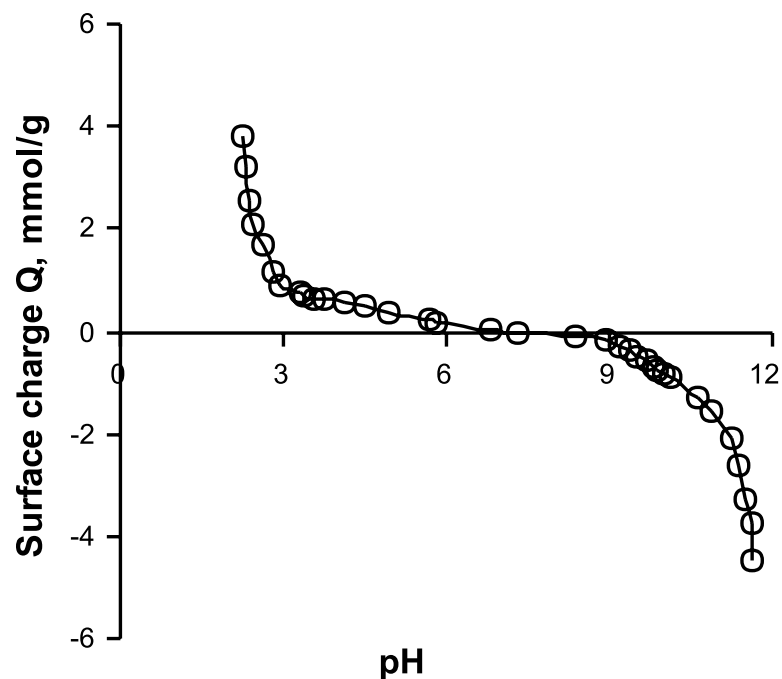

Figure 1. Surface charge of the adsorbent as a function of $\mathrm{pH}$

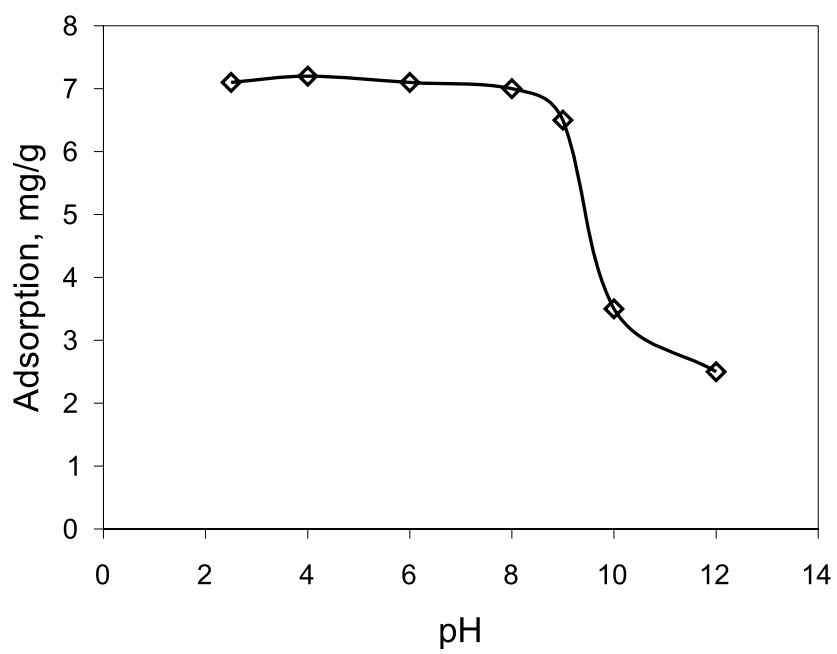

Figure 2. Effect of $\mathrm{pH}$ on the adsorption of phenol onto burned water hyacinth (Initial concentration $C_{0}=50 \mathrm{mg} / \mathrm{L}$, Volume of solution $V=150 \mathrm{ml}$, Amount of adsorbent $M=1.0 \mathrm{gm}$, Temperature $=27 \pm 2^{\circ} \mathrm{C}$ )

\section{Effect of pH on phenol adsorption}

The initial $\mathrm{pH}$ of adsorption medium is one of the most important parameters affecting the adsorption process. Fig. 2 shows the effect of $\mathrm{pH}$ on the adsorption of phenol. From Fig. 2, it was observed that the uptake of phenol by $\mathrm{BWH}$ was almost constant in the $\mathrm{pH}$ range of $2.5-9$. When $\mathrm{pH}$ exceeded 9, the removal dropped suddenly. This can be attributed to the dependency of phenol ionization on the $\mathrm{pH}$ value and point of zero charge (PZC) for BWH. Fig. 3 shows, the FTIR spectrum of BWH. As seen from the figure, BWH contains several functional groups such as hydroxyl peak at $3410 \mathrm{~cm}^{-1}$ and asymmetric carboxylate peak at $1622 \mathrm{~cm}^{-1}$. The peaks observed at 1110 $\mathrm{cm}^{-1}$ could be assigned to $\mathrm{C}-\mathrm{O}$ stretching of ether groups.

The $\mathrm{pH}$ primarily affects the degree of ionization of phenol and the surface properties of BWH. The ionic fraction of phenolate ion $\left(\phi_{\text {ions }}\right)$ can be calculated from the following equation ${ }^{\mathbf{1 8}}$ :

$\phi_{\text {ions }}=\frac{1}{1+10^{p K a-p H}}$

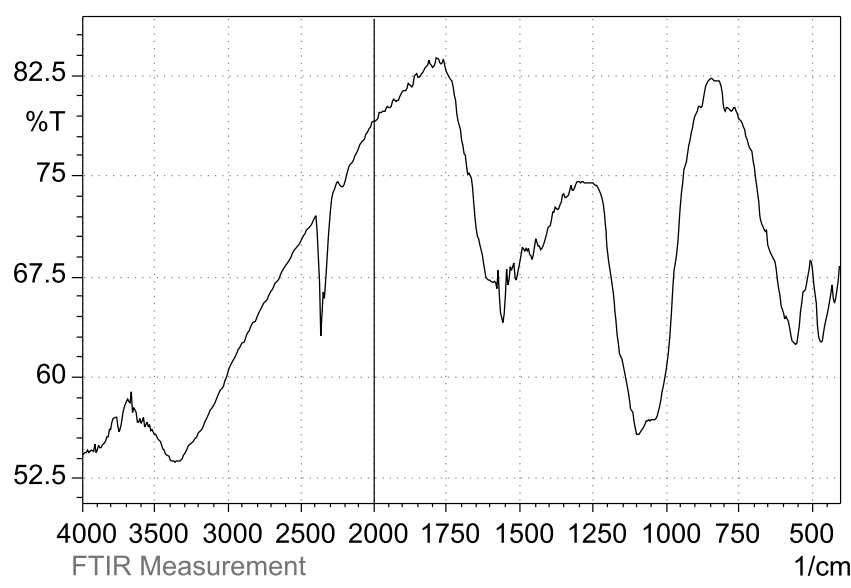

Figure 3. The FTIR spectra of burned water hyacinth

Obviously, $\phi_{\text {ions }}$ increases as the $\mathrm{pH}$ value increased. Considering $\mathrm{p} K a$ of 9.89 of phenol, it is present in a molecular form, which has polar characteristic, in the aqueous phase when $\mathrm{pH}$ is less than 9 , however, it is present in the form of the phenolate ion when the $\mathrm{pH}$ of the equilibrium solution is higher than 9.89. The pHpzc at the point of zero charge of $\mathrm{BWH}$ is about $8.8 \pm 0.2$ (Fig. 1). At $\mathrm{pH}$ values above pHpzc, the surface of $\mathrm{BWH}$ particles is negatively charged. Therefore, phenol will be adsorbed to a lesser extent at $\mathrm{pH}$ above $\mathrm{pHpzc}$ due to the repulsive forces between phenolate ion and the negatively charged surface of the adsorbent due to $\mathrm{COO}^{-}$groups and deprotonated hydroxyl groups. At $\mathrm{pH}$ below $\mathrm{pHpzc}$, polar phenol molecules can be adsorbed on the protonated surface of the adsorbent according to the following equations:

$\equiv \mathrm{M}+\mathrm{H}^{+} \leftrightarrow \equiv \mathrm{MH}^{+}$,

$\equiv \mathrm{MH}^{+}+$phenol $\leftrightarrow \equiv \mathrm{MH}^{+}$---phenol

Overall reaction can be written as

$\equiv \mathrm{M}+\mathrm{H}^{+}+$phenol $\leftrightarrow \equiv \mathrm{MH}^{+}$---phenol

where $\mathrm{M}$ is the adsorbent.

\section{Effect of contact time and initial concentrations}

The adsorption data for the uptake of phenol versus contact time at different initial concentrations is presented in Fig. 4. The results showed that the equilibrium time

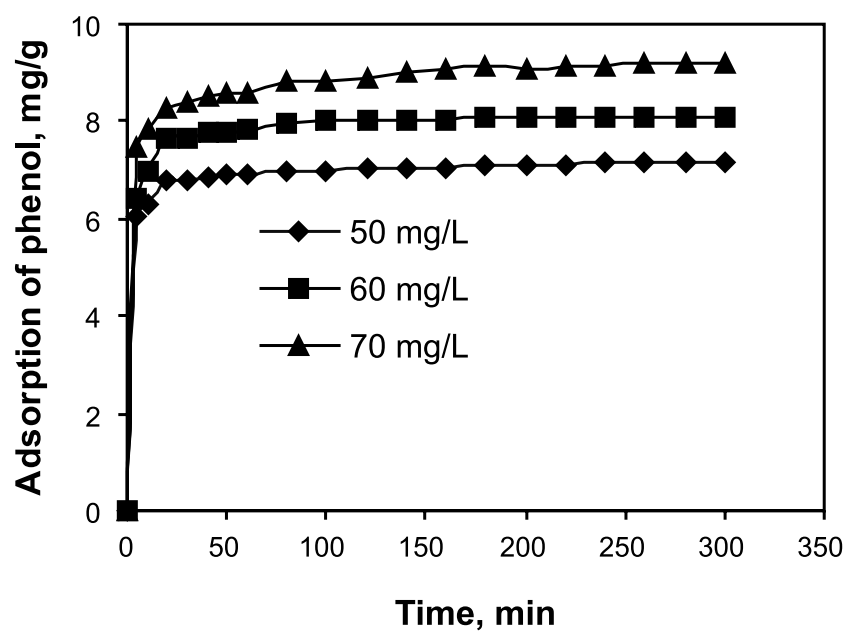

Figure 4. Effect of contact time and initial concentrations on the adsorption of phenol onto burned water hyacinth (Initial concentration $C_{0}=50,60$ and 70 $\mathrm{mg} / \mathrm{L}, \mathrm{pH}=6 \pm 0.5$, Volume of solution $V=200$ $\mathrm{ml}$, Amount of adsorbent $M=0.50 \mathrm{gm}$, Temperature $=27 \pm 2^{\circ} \mathrm{C}$ ) 
required for the adsorption of phenol on BWH was almost 120 minutes $(2 \mathrm{~h}$ ). However, for subsequent experiments, the samples were left for $5 \mathrm{~h}$ to ensure equilibrium. These results also indicated that up to $90-95 \%$ of the total amount of phenol uptake was found to occur in the first rapid phase $(30 \mathrm{~min})$ and thereafter the sorption rate was found to decrease. The higher sorption rate at the initial period (first $30 \mathrm{~min}$ ) may be due to an increased number of vacant sites on the adsorbent available at the initial stage, as a result there exist increased concentration gradients between the adsorbate in the solution and the adsorbate on the adsorbent surface. This increase in concentration gradients tends to increase in phenol sorption at the initial stages. As time precedes this concentration is reduced due to the accumulation of phenol particles in the vacant sites leading to a decrease in the sorption rate at the later stages from 30 to $300 \mathrm{~min}^{23}$. It was also seen that an increase in initial concentration resulted in increased phenol uptake.

\section{Effect of adsorbent dosage}

In order to investigate the effect of mass of adsorbent on the adsorption of phenol, a series of adsorption experiments was carried out with different adsorbent dosage at an initial phenol concentration of $70 \mathrm{mg} / \mathrm{L}$. Fig. 5 shows

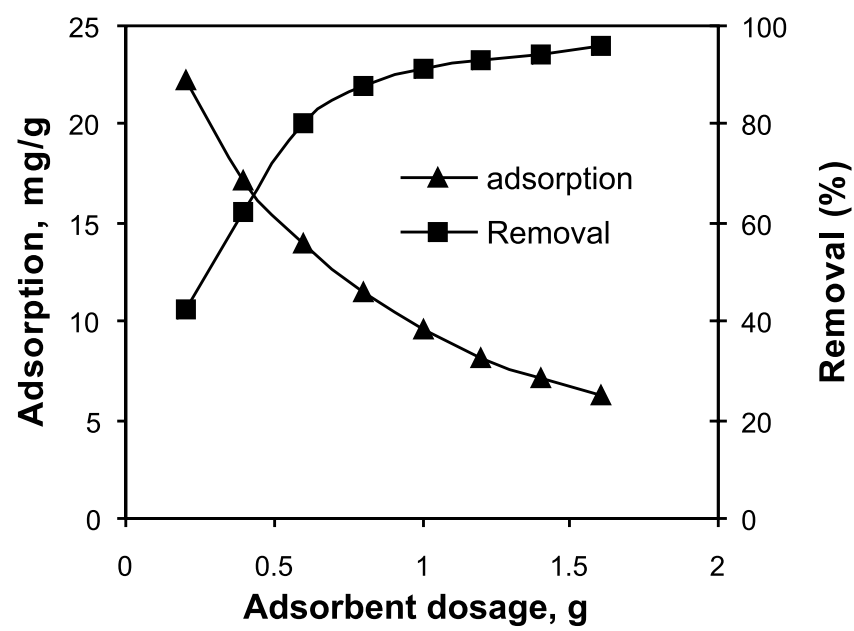

Figure 5. Effect of adsorbent dosage on the adsorption of phenol onto burned water hyacinth (Initial concentration $C_{0}=70 \mathrm{mg} / \mathrm{L}, \mathrm{pH}=6 \pm 0.5$, Volume of solution $V=150 \mathrm{ml}$, Temperature $=27 \pm 2^{\circ} \mathrm{C}$ )

the effect of adsorbent dosage on the removal of phenol. The percentage removal of phenol increased with the increase in adsorbent dosage. This can be attributed to increased adsorbent surface area and availability of more adsorption sites resulting from the increase adsorbent dosage. But the amount of phenol adsorbed per unit mass of BWH decreased with increase in the adsorbent dosage.

\section{Adsorption equilibrium}

Equilibrium study on adsorption provides information on the capacity of the adsorbent. An adsorption isotherm is characterized by certain constant values, which express the surface properties and affinity of the adsorbent and can also be used to compare the adsorptive capacities of the adsorbent for different pollutants. Equilibrium data can be analyzed using the commonly known adsorption isotherms, which provide the basis for the design of adsorption systems. The most widely used isotherm equa- tion for the modeling of the adsorption data is the Langmuir equation, which is valid for monolayer sorption onto the surface with a finite number identical site and is given by eq. (3).

$q_{e}=\frac{q_{0} K_{L} C_{e}}{1+K_{L} C_{e}}$

Where $q_{0}$ and $K_{L}$ are Langmuir parameters related to maximum adsorption capacity and free energy of adsorption, respectively. $C_{e}$ is the equilibrium concentration in the aqueous solution and $q_{e}$ is the equilibrium adsorption capacity of the adsorbent. The linearized form of Langmuir equation can be written as

$\frac{1}{q_{e}}=\frac{1}{q_{0}}+\frac{1}{q_{0} K_{L}} \cdot \frac{1}{C_{e}}$

The Langmuir constant $q_{0}$ and $K_{L}$ can be calculated by plotting $1 / q_{e}$ versus $1 / C_{e}$.

The Freundlich model is an empirical equation based on sorption on the heterogeneous surface. It is given as $q_{e}=K_{F} C_{e^{\frac{1}{n}}}$

Where $K_{F}$ and $n$ are the Freundlich constants that indicate adsorption capacity and adsorption intensity, respectively.

The linearized form of Freundlich isotherm can be written as

$\ln q_{e}=\ln K_{F}+\frac{1}{n} \ln C_{e}$

The value of $K_{F}$ and $n$ can be calculated by plotting $\ln$ $q_{e}$ versus $\ln C_{e}$.

Fig. 6 and Fig. 7 show the Langmuir and Freundlich curves for phenol adsorption onto BWH, respectively. The isotherm constants and correlation coefficients are shown in Table 1. From Fig. 6 and Fig. 7, it was observed that the equilibrium data were very well represented by the Langmuir isotherm equation when compared to the Freundlich equation. The sorption equilibrium data fitted the Langmuir and Freundlich equations with correlation coefficients values of 0.99 and 0.96 , respectively. The best fit of the equilibrium data in the Langmuir isotherm expression predicted the monolayer coverage of phenol onto

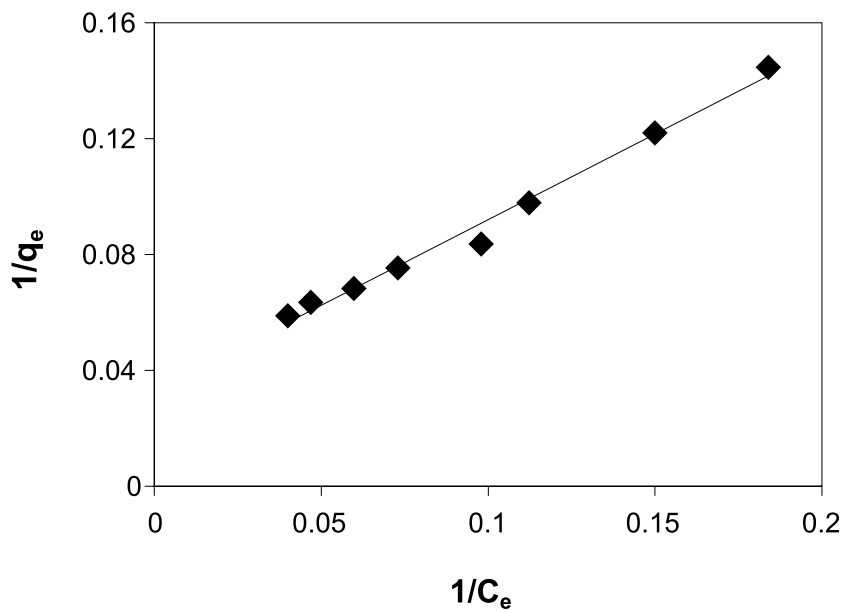

Figure 6. Langmuir isotherm for phenol adsorption onto burned water hyacinth (Initial concentration $C_{0}=$ $40,50,60,70,80,90,100$ and $110 \mathrm{mg} / \mathrm{L}, \mathrm{pH}=$ $6 \pm 0.5$, Volume of solution $V=150 \mathrm{ml}$, Amount of adsorbent $M=0.75 \mathrm{gm}$, Temperature $=27 \pm 2^{\circ} \mathrm{C}$ ) 
Table 1. Comparison of isotherm constants and adsorption capacity of different adsorbents for phenol adsorption

\begin{tabular}{|c|c|c|c|c|}
\hline \multirow[b]{2}{*}{ Adsorbents } & \multicolumn{2}{|c|}{ Freundlich isotherm } & \multicolumn{2}{|c|}{ Langmuir isotherm } \\
\hline & $\begin{array}{c}K_{F} \\
(\mathrm{mg} / \mathrm{g})(\mathrm{L} / \mathrm{g})^{1 / n}\end{array}$ & $n$ & $K_{L}(\mathrm{~L} / \mathrm{mg})$ & $q_{\circ}(\mathrm{mg} / \mathrm{g})$ \\
\hline $\mathrm{Coal}^{25}$ & 1.44 & 3.14 & 0.008 & 13.23 \\
\hline Residual coal $^{25}$ & 6.35 & 3.66 & 0.013 & 45.45 \\
\hline Coal treated with $\mathrm{H}_{3} \mathrm{PO}_{4}{ }^{25}$ & 7.27 & 2.55 & 0.002 & 142.8 \\
\hline Rice husk $^{25}$ & 0.11 & 2.14 & 0.001 & 4.508 \\
\hline Coke breeze $^{25}$ & 0.91 & 0.35 & 0.001 & 0.172 \\
\hline Neutralized red mud ${ }^{26}$ & 0.51 & 2.43 & 0.051 & 4.127 \\
\hline Rice husk ash ${ }^{27}$ & 1.26 & 1.63 & 0.0383 & 18.62 \\
\hline Activated coal ${ }^{28}$ & 0.97 & 0.79 & 0.065 & 1.481 \\
\hline Resin AP $-246^{28}$ & 0.11 & 0.35 & 0.584 & 0.071 \\
\hline Carbonized beet pulp ${ }^{6}$ & 25.58 & 4.64 & 89.96 & 0.0639 \\
\hline Chitin $^{\prime}$ & 1.51 & 2.21 & 0.0124 & 24.15 \\
\hline Bentonite $^{10}$ & 0.10 & 2.56 & 0.0158 & 0.842 \\
\hline Titanium oxide $^{12}$ & 1.12 & 0.50 & 0.01599 & 19.1656 \\
\hline $\begin{array}{l}\text { Burned water hyacinth } \\
\text { (This study) }\end{array}$ & 2.62 & 1.64 & 0.0555 & 30.49 \\
\hline
\end{tabular}

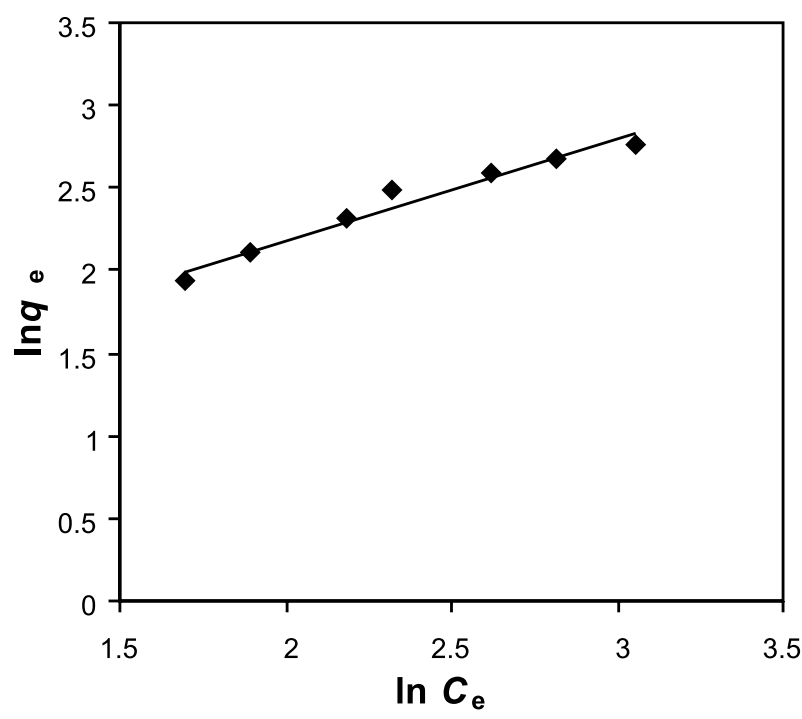

Figure 7. Freundlich isotherm for phenol adsorption onto burned water hyacinth (Initial concentration $C_{0}=$ $40,50,60,70,80,90,100$ and $110 \mathrm{mg} / \mathrm{L}, \mathrm{pH}=$ $6 \pm 0.5$, Volume of solution $V=150 \mathrm{ml}$, Amount of adsorbent $M=0.75 \mathrm{gm}$, Temperature $=27 \pm 2^{\circ} \mathrm{C}$ )

BWH. From Table 1, it was also observed that the maximum sorption capacity of BWH for phenol was found to be $30.49 \mathrm{mg} / \mathrm{g}$. A comparison of isotherm constants and adsorption capacity for the adsorption of phenol by nonconventional adsorbents are presented in Table 1.

To determine if the phenol adsorption process by $\mathrm{BWH}$ is favorable or unfavorable for the Langmuir type adsorption process, the isotherm shape can be classified by a

\begin{tabular}{|l|l|}
\hline Value of $R_{L}$ & Type of isotherm \\
\hline$R_{L}>1$ & Unfavorable \\
\hline$R_{L}=1$ & Linear \\
\hline $0<R_{L}<1$ & Favorable \\
\hline$R_{L}=0$ & Irreversible \\
\hline
\end{tabular}

term $R_{L}$, a dimensionless constant separation factor, which is defined below ${ }^{24}$

$R_{L}=\frac{1}{1+K_{L} C_{0}}$

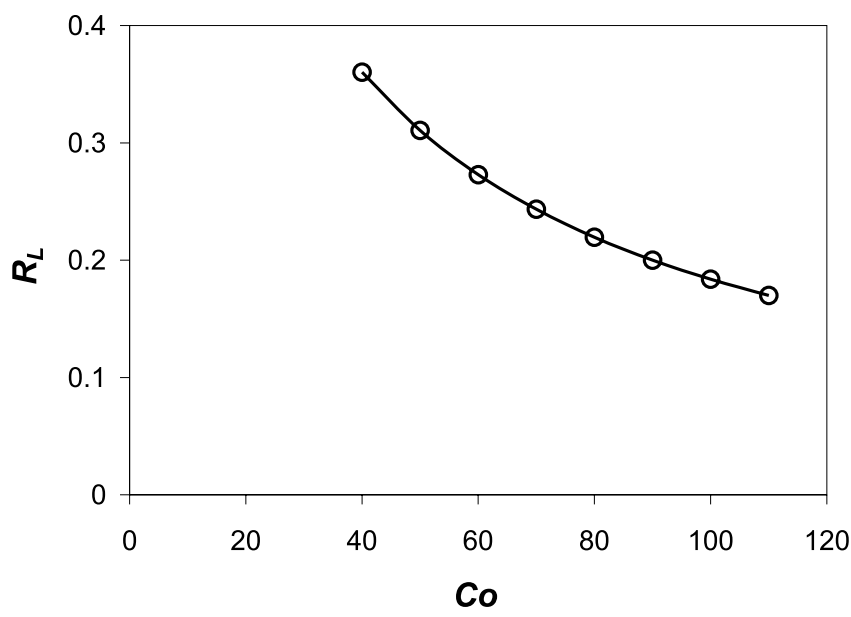

Figure 8. Separation factor for phenol sorption onto burned water hyacinth (Initial concentration $C_{0}=40,50$, $60,70,80,90,100$ and $110 \mathrm{mg} / \mathrm{L}, \mathrm{pH}=6 \pm 0.5$, Volume of solution $V=150 \mathrm{ml}$, Amount of adsorbent $M=0.75 \mathrm{gm}$, Temperature $=27 \pm 2^{\circ} \mathrm{C}$ )

where $R_{L}$ is a dimensionless separation factor, $C_{0}$ is the initial solution concentration and $R_{L}$ is Langmuir constant $(\mathrm{L} / \mathrm{mg})$. The parameter indicates the shape of the isotherm accordingly:

The calculated $R_{L}$ values, ranging from 0.17 to 0.36 for different initial phenol concentration is shown in Fig. 8. The values of $R_{L}$ in the present investigation have been found to be below 1.0 for phenol showing that the adsorption of phenol is very favorable.

\section{Adsorption kinetics}

Kinetic models are used to examine the rate of the adsorption process and the potential rate-controlling step. In the present work, the kinetic data obtained from batch studies have been analyzed by using the pseudo-first-order and the pseudo-second-order models.

The first order equation of Lagergren is generally expressed as follows ${ }^{29}$

$\frac{d q}{d t}=k_{1}\left(q_{e}-q\right)$

where $q$ is the amounts of phenol adsorbed $\left(\mathrm{mg} \mathrm{g}^{-1}\right)$ at time $t(\mathrm{~min})$, and $k_{1}$ is the rate constant of the pseudo-first-order sorption $\left(\mathrm{min}^{-1}\right)$.

The integrated form of Eq.(8) becomes 
Table 2. Pseudo-first-order kinetic constants for the adsorption of phenol onto burned water hyacinth

\begin{tabular}{|l|c|c|c|c|}
\hline $\mathrm{C}_{0}(\mathrm{mg} / \mathrm{L})$ & $q_{e, \exp }(\mathrm{mg} / \mathrm{g})$ & $q_{\mathrm{e}, \text { cal }}(\mathrm{mg} / \mathrm{g})$ & $k_{1}\left(\mathrm{~min}^{-1}\right)$ & $r_{1}^{2}$ \\
\hline 50 & 13.48 & 3.48 & 0.0103 & 0.9751 \\
\hline 60 & 15.30 & 4.46 & 0.0105 & 0.9853 \\
\hline 70 & 16.65 & 4.53 & 0.0074 & 0.9124 \\
\hline
\end{tabular}

$\ln \left(q_{e}-q\right)=\ln q_{e}-k_{1} t$

A plot of $\ln \left(q_{e}-q\right)$ against $t$ should give a linear relationship with the slop $k_{1}$ and intercept of $\ln q_{e}$.

The pseudo-second-order kinetic rate equation is expressed as follows ${ }^{30}$

$\frac{d q}{d t}=k_{2}\left(q_{e}-q\right)^{2}$

Where $k_{2}$ is the rate constant of the pseudo-secondorder sorption $\left(\mathrm{g} \mathrm{mg}^{-1} \mathrm{~min}^{-1}\right)$. The integrated form of Eq. (10) becomes

$\frac{t}{q}=\frac{1}{k_{2} q_{e}{ }^{2}}+\frac{1}{q_{e}} t$

If the second order kinetic equation is applicable, the plot of $t / q$ against $t$ of Eq. (11) should give a linear relationship. The $q_{e}$ and $k_{2}$ can be determined from the slope and intercept of the plot.

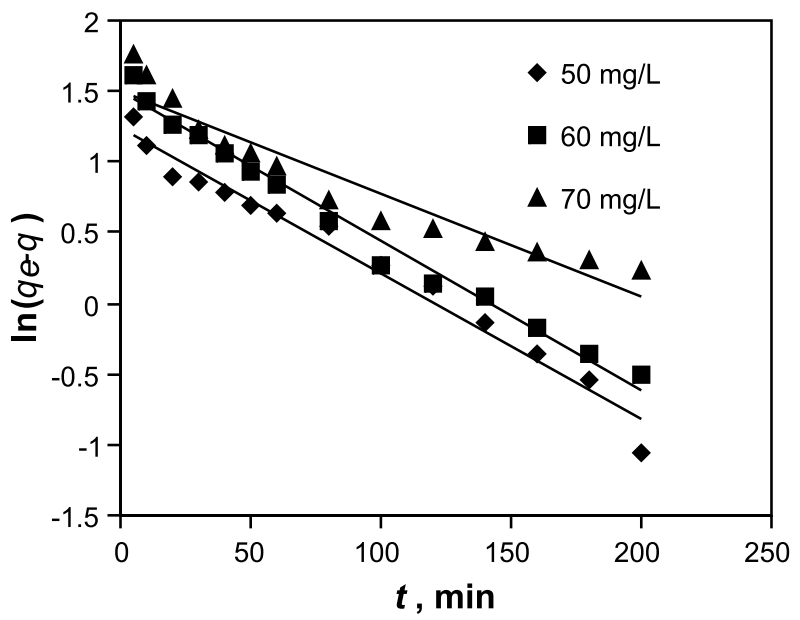

Figure 9. Pseudo-first-order kinetics for the adsorption of phenol onto burned water hyacinth (Initial concentration $C_{0}=50,60$ and $70 \mathrm{mg} / \mathrm{L}, \mathrm{pH}=6 \pm 0.5$, Volume of solution $V=200 \mathrm{ml}$, Amount of adsorbent $M=0.50 \mathrm{gm}$, Temperature $=27 \pm 2^{\circ} \mathrm{C}$ )

The plot of the linearized form of the pseudo first-order equation is shown in Fig. 9. The pseudo first-order rate constant $k_{1}$, the amount of phenol adsorbed at equilibrium, and correlation coefficient are shown in Table 2. The results showed that the correlation coefficients obtained for all initial concentrations, $C_{0}$ were higher than 0.9. Although the correlation coefficient values were higher than 0.9 , the experimental $q_{e}$ did not agree with the calculated ones, obtained from the linear plots. Therefore,

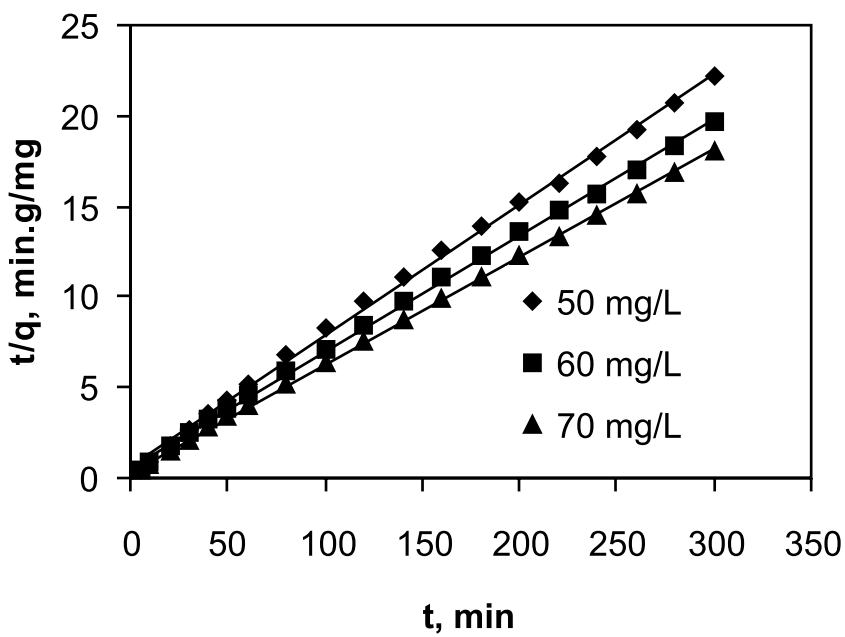

Figure 10.Second order kinetics for adsorption of phenol onto burned water hyacinth (Initial concentration $C_{0}=50$, 60 and $70 \mathrm{mg} / \mathrm{L}, \mathrm{pH}=6 \pm 0.5$, Volume of solution $V=200 \mathrm{ml}$, Amount of adsorbent $M=0.50 \mathrm{gm}$, Temperature $=27 \pm 2^{\circ} \mathrm{C}$ )

the pseudo-first-order kinetic model did not describe the adsorption results of phenol onto BWH.

Fig. 10 shows the linearized form of the pseudo-secondorder kinetic model. The pseudo-second-order constant $k_{2}$, amount of phenol adsorbed at equilibrium $q_{e}$, and the corresponding correlation coefficient values are given in Table 3. From Table 3, it was noticed that the $r_{2}^{2}$ values were found to be higher than that of $r_{1}^{2}$ at all initial phenol concentrations. The theoretical $q_{e}$ values were closer to the experimental $q_{e}$ values. In the view of these results, it can be said that the pseudo-second -order kinetic model provided a good correlation for the adsorption of phenol onto BWH in contrast to the pseudo-first-order model.

\section{CONCLUSION}

The results indicated that adsorption capacity of the adsorbent was considerably affected by the initial $\mathrm{pH}$, initial phenol concentration, contact time and the adsorbent dosage. The amount of phenol adsorbed increased with increasing the initial phenol concentration. The uptake of phenol took place at a $\mathrm{pH}$ in the range of 2.5 - 9. Then the adsorption of phenol decreased with increasing the $\mathrm{pH}$. The $\mathrm{pH}$ at the point of zero charge was determined by the titration method and was found to be $8.8 \pm 0.2$.

The equilibrium data fitted very well in a Langmuir isotherm equation, confirming the monolayer sorption capacity of phenol onto BWH with a monolayer sorption capacity of $30.49 \mathrm{mg} / \mathrm{g}$.

The pseudo-first-order and the pseudo-second-order kinetic models were used to analyze the data obtained for phenol adsorption onto BWH. The result indicated that the pseudo-second-order equation provided the better correlation for the adsorption data.

Table 3. Pseudo-second-order kinetic constants for the adsorption of methylene blue onto burned water hyacinth

\begin{tabular}{|c|c|c|c|c|}
\hline $\mathrm{C}_{0}(\mathrm{mg} / \mathrm{L})$ & $q_{e, \text { exp }}(\mathrm{mg} / \mathrm{g})$ & $q_{e, \text { cal }}(\mathrm{mg} / \mathrm{g})$ & $k_{2}(\mathrm{~g} / \mathrm{mg} \min )$ & $r_{2}{ }^{2}$ \\
\hline 50 & 13.48 & 13.79 & 0.0083 & 0.9985 \\
\hline 60 & 15.30 & 15.65 & 0.0067 & 0.9987 \\
\hline 70 & 16.65 & 16.86 & 0.0099 & 0.9997 \\
\hline
\end{tabular}




\section{LITERATURE CITED}

1. Mostafa, M. R., Sarma, S. E. \& Yousef, A. M. (1989). Removal of organic pollutants from aqueous solution: Part 1. Adsorption of phenols by activated carbon. Ind. J. Chem. 28A, $946-1948$.

2. Dutta, N. N., Patil, G. S. \& Brothakur, S. (1992). Phase transfer catalyzed extraction of phenolic substances from aqueous alkaline stream. Sep. Sci. Technol., 27 (11), 1435 1448. DOI: $10.1080 / 01496399208019435$.

3. El- Geundi, M. S. (1997). Adsorbents for industrial pollution control. Adsorp. Sci. Technol., 15 (10), 777 - 787.

4. McKay, G., Prasad, G. R. \& Mowli, P. R. (1986). Equilibrium studies for the adsorption of dyestuffs from aqueous solutions by low-cost materials. Water, Air Soil Poll. 29 (3), 273 - 283. DOI: 10.1007/BF00158759.

5. Mohanty, K., Das, D. \& Biswas, M.N. (2005). Adsorption of phenol from aqueous solutions using activated carbons prepared from Tectona grandis sawdust by $\mathrm{ZnCl}_{2}$ activation. Chem. Eng. J. 115(1-2) 121 - 131. DOI: 10.1016/ j.cej.2005.09.016.

6. Dursun, G., Cicek, H. \& Dursun, A.Y. (2005). Adsorption of phenol from aqueous solution by using carbonized beet pulp. J. Hazard. Mater. B125 (1-3), 175 - 182. DOI: 10.1016/j.jhazmat.2005.05.023.

7. Dursun, A. Y. \& Kalayci, C. S. (2005). Equilibrium, Kinetic and thermodynamic studies on adsorption of phenol onto chitin. J. Hazard. Mater. B123 (1-3), 151 - 157. DOI: 10.1016/j.jhazmat.2005.03.034.

8. Al-Asheh, S. A., Banat, F. \& Aitah, L. A. (2003). Adsorptioon of phenol using different types of activated bentonites. Sep. Purif. Technol. 33 (1), 1 - 10. DOI: 10.1016/ S1383-5866(02)00180-6.

9. Vigiraraghavan, T. \& Alfaro, F. M. (1998). Adsorption of phenol from wastewater by peat, fly ash and bentonite. J. Hazard. Mater. 57 (1-3), 59 - 70. DOI: 10.1016/S03043894(97)00062-9.

10. Banat, F. A., Al-Bashir, B., Al-asheh, S. \& Hayajneh, O.(2000). Adsorption of phenol by bentonite. Environ. Poll. 107 (3), 391 - 398. DOI:10.101/S0269-7491(99)00173-6.

11. Roostaei, N. \& Tezel, F. H. (2004). Removal of phenol from aqueous solutions by Adsorption. J. Environ. Manage. 70 (2), 157 - 164. DOI:10.101/j.jenvman.2003.11.004.

12. Bekkouche, S., Bouhelassa, M., Salah, N. H. \& Meghlaoui, F. Z. (2004). Study of adsorption of phenol on titanium oxide $\left(\mathrm{TiO}_{2}\right)$. Desalination, 166, 355 - 362 . DOI:10.1016/j.desal.2004.06.090.

13. Nakagawa, K., Namba, A., Mukai, S. R., Tamon, H., Ariyadejwanich, P. \& Tanthapanichakoon, W. (2004). Adsorption of phenol and reactive dye from aqueous solution on activated carbons derived from solid wastes. Water Res. 38 (7), 1791 - 1798. DOI: 10.1016/j.watres.2004.01.002.

14. Tancredi, N., Medero, N., Möller, F., Piriz, J., Plada, C. \& Cordero, T. (2004). Phenol adsorption onto powdered and granular activated carbon, prepared from Eucalyptus wood. J. Colloid Interf. Sci. 279 (2), 357 - 363. DOI:10.1016/ j.jis. 2004.06.067.

15. Tanthapanichakoon, W., Ariyadejwanich, P., Japthong, P., Nakagawa, K., Mukai, S. R. \& Tamon, H., (2005). Adsorption- desorption characteristics of phenol and reactive dyes from aqueous solution on mesoporous activated carbon prepared from waste tires. Water Res. 39 (7), 1347 1351. DOI: 10.1016/j.watres.2004.12.044.

16. Rao, M., Parwate, A.V. \& Bhole, A.G. (2002). Removal of $\mathrm{Cr}^{6+}$ and $\mathrm{Ni}^{2+}$ from aqueous solution using bagasse and fly ash. Waste Manage. 22 (7), 821 - 830. DOI:10.1016/S0956053X(02)00011-9.

17. Akbal, F. (2005). Sorption of phenol and 4- chlorophenol onto pumice treated with cationic surfactant. J. Environ. Manage.74 (3), 239 - 244. DOI:10.1016/j.jenvman.2004.10.001
18. Calace, N., Nardi, E., Petronio B. M. \& Pietroletti, M. (2002). Adsorption of phenols by papermill sludges. Environ. Poll. 118 (3), 315 - 319. DOI: 10.1016/S0269-7491(01)00303-7.

19. El-Sayed, A.M. (2003). Effects of fermentation methods on the nutritive value of water hyacinth for Nile tilapia. Oreochromis niloticus (L.) fingerlings, Aquaculture, 218 (1-4), 471 - 478. DOI: 10.1016/S0044-8486(02)00252-1.

20. Ganesh, P.S., Ramasamy, E.V., Gajalakshmi, S. \& Abbasi, S.A. (2005). Extraction of volatile fatty acids (VFAs) from water hyacinth using inexpensive contraptions, and the use of the VFAs as feed supplement in conventional biogas digesters with concomitant final disposal of water hyacinth as vermicompost. Biochem. Eng. J. 27 (1), 17 - 23. DOI: 10.1016/j.bej.2005.06.010.

21. Grandi, A. (1981). Use of Water Hyacinth in diets for rabbits. Coniglicol. 18, $43-48$.

22. Kiefer, E., Sigg, L., \& Schosseler, P. (1997). Chemical and spectroscopic charactirization of algae Surfaces. Environ. Sci. Technol. 31(3),759 - 764. DOI: 10.1021/es960415d.

23. Vadivelan, V., \& Kumar, K.V., (2005). Equilibrium, kinetics, mecknism, and process design for the sorption of methylene blue onto rice hush. J. Colloid Interf. Sci. 286 (1), 90 - 100. DOI: 10.1016/j.jcis.2005.01.007.

24. Weber, T.W. \& Chakraborti, R.K. (1974). Pore and solid diffusion models for fixed bed adsorbers. J. Am. Ins. Chem. Eng. 20, 228 - 236.

25. Ahmaruzzaman, M., \& Sharma, D.K. (2005). Adsorption of phenols from wastewater. J. Colloid Interf. Sci. 287 (1), 14 - 24. DOI: 10.1016/j.jcis.2005.01.075.

26. Tor, A., Cengeloglu, Y., Aydin, M. E., \& Ersoz, M. (2006). Removal of phenol from aqueous phase by using neutralized red mud. J. Colloid Interf. Sci. 300 (2), 498 - 503. DOI: $10.1016 /$ j.jcis.2006.04.054

27. Uddin, M. T., Islam, M. S., Islam M. A. \& Abedin, M. Z. (2006). Removal of phenol from aqueous solution by rice husk ash. Bangladesh J Environ. Sci. 12 (2), 344 - 347.

28. Vazquez, I., Rodriguez-Iglesias, J., Maranon, E., Castrillon, L., \& Alvarez, M. (2007). Removal of residual phenols from coke wastewater by adsorption. J. Hazard. Mater. 147 (1-2), 395-400. DOI: 10.1016/j.jhazmat.2007.01.019.

29. Lagergren, S. (1898). Zur theorie der sogenannten adsorption geloster stoffe, Kungliga Svenska Vetenkapsakademiens. Handl. 24, 1 - 39.

30. Ho, Y.S., \& Mckay, G. (1999). Pseudo-second-order model for sorption process. Process Biochem. 34 (5), 451 465. DOI: 10.1016/S0032-9592(98)00112-5. 